\title{
UBERSICHT DES INHALTS
}

Panhellenische Götter . . . . . . . . . . . . . 1

Uberblick über die Stämme und Staaten des Mutterlandes S. I bis 6. Einfluß des Orients 7. Der Heroenglaube 8-19. Herakles 20-26. Der delphische Apollon 26-42. Die eleusinischen Mysterien 42-59. Dionysos 59-80. Hellas im sechsten Jahrhundert 81-90. Nationale Agone 89-90. Chorlyrik, Drama 91 96. Die theophoren Namen 97-98. Weihgeschenke, Heiligtümer, Tempelbau, Götterbilder, Malerei 99-I05. Die Hellenen geistig noch keine Einheit 105-107. Gegensatz von Ost und West ro7-ro9. Sappho,Alkaios ro9-1 ro. Mimnermos, Anakreon, Alkman, Stesichoros, Tyrtaios r ro-rir. Archilochos, Semonides, Phokylides I r 2-II4. Solon Ir 4-irg. Menschliche Verantwortung und Schuld I I 5-1 I7. Sünden und ihre Bestrafung durch Götter und Menschen I 1 7-1 24. Die Griechen frei von Pessimismus und Optimismus r 25-126. Pindar 126-130. Aischylos 130-136. Uberblick über die fortlebenden Götter: Hestia, Themis, Nemesis 137, Musen 1 38, Ares, Hephaistos I 39-141, Hera 141-142, Poseidon 142-I 44, Hermes I 43-I 44, Artemis I45-I 48, Aphrodite 148-153, Dionysos I5 4-155, Demeter, Persephone-Kore, Iakchos 156-160, Athena 160-165, Apollon 166-169, Zeus 169 bis 171 . Herakles 172. Fremde Götter 172-174. Pan 174-176. Götter außerhalb des Staatskultus, wie Ekecheiria, Eirene, Nike $176-178$, Eros $178-180$. Totengericht $180-182$. Verbot der Fleischnahrung (Kureten-Korybanten, Pythagoras) ${ }_{1} 83$ bis 190. Orpheus (Orphika) 190-202. Ablehnung der Mystik in Hellas 203. Herodot 203-205. Thales und die ionische Wissenschaft 205-206. Xenophanes 207. Herakleitos 207-209. Parmenides 209. Anaxagoras, Archelaos 209-211. Protagoras und die Sophistik, Euripides 2ri-216. Entsittlichung, Tyrannis 217-218. Reaktion gegen die Aufklärung 219-220. Asklepios 220-229. Sophokles 229-233. Sokrates 233-235. Griechenland im vierten Jahrhundert 235. Thukydides 236-237. Xenophon 237-239. Isokrates 239-240. Die Philosophie im vierten Jahrhundert 240-242. Demokrit 242-243. Platon 244-25s. Rückblick auf die Entwicklung der hellenischen Religion $255-257$. 
Weltgeltung und Niedergang des Hellenentumes . . . . . 258

Griechenland und Athen im vierten Jahrhundert 258-259. Keine Vergöttlichung der Menschen 259-260. Alexander der Große 260-264. Königskult der hellenistischen Zeit 264-267. Euemeros 267-268. Bestimmender Einfluß der philosophischen Lehrer 268-270. Diogenes, Krates von Theben 270-272. Kerkidas 272. Kyniker 273-274. Rhetorik 274-275. Die Philosophie als magistra vitae 275-276. Akademie 276-278. Aristoteles und der Peripatos 279-283. Epikur und seine Schule 283-286. Stoa 287-294. Naturwissenschaft 294-295. Tyche und ihr Kult 295 bis 305 . Kampf der Philosophen gegen den Tycheglauben 305 bis 306. Fortleben der Seele, Jenseitsvorstellungen 306-3 Ir. Kallimachos 3II-312. Die hellenistische Dichtung 3II-3r4. Die neue Komödie 315-316. Mystik als Unterströmung des Rationalismus 317-318. Hellenisierung der Götter in Kleinasien 318-319. Priapos 320-321. Semitische und iranische Götter in der hellenistischen Zeit 322-323. Die griechischen Götter im Westen 323-334. Das Griechentum in Agypten 334-336.

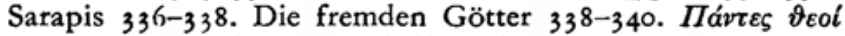
340-341. Der Kultus der panhellenischen Götter 341-345. Поo $\pi a l$ und Lectisternia 345-349. Epiphanien, neue Spiele, Asylie 350-352. Die Schutzgötter der Städte 352-353. Die Tempelbauten 353-354. Die bildende Kunst 355-356. Eroten und Psychen 356-36o. Der pergamenische Altar $361-363$. Private Kultgenossenschaften $36_{3}-365$. Die dionysischen Mysterien als die einzigen von allgemeiner und dauernder Bedeutung 365-381. Die Stiftungen des Artemidoros von Perge in Thera 382-385.

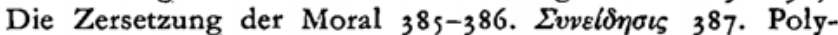
bios 388-389. Panaitios 389-395. Astrologie 395-396. Poseidonios 396-405. Skepsis (Ainesidemos) und Vermittlungsphilosophien (Neupythagoreer, Antiochos von Askalon) 405-407. Die Theologie des Poseidonios und seine Stellung zum Kultus 407-410. Apollodor $\pi$. $\theta \varepsilon \tilde{\omega} v$ 410-4I 2. Lokalschriften, Sammlungen von theologischen Stoffen 413-414. Verfall der griechischen Welt 41 4-41 5. Gesteigerte Pflege deralten Kulte, insbesondere in Athen 416-417. Mithradates. Verwüstung und Verarmung 417-420. Entwürdigung der Griechen 420. Der Hellenismus tot 420 .

Restauration und Untergang des Hellenentumes . . . . . 421

Augustus.Der Kaiserkult42I-425. RömischesNationalgefühl 425-426. Die Restauration desAugustus 426-427.Zersetzung der römischen Religion und Moral durch das Griechentum 427-428. 
Cicero 429. Horaz 430-43I. Vergil 43I. Die bildende Kunst des Klassizismus 43I-433. Die asianische Rhetorik. Sieg des Attizismus 433-436. Rom maßgebend für die Griechen 436 bis 437 . Neupythagoreismus $437-439$. Kynismus 439 . Die Flavier. Der Schwerpunkt des geistigen Lebens rückt in den Osten 439-44I. Rhetorik (Quintilian) 44I-445. Unterschied der Bildung im Osten und Westen 445-446. Die Philosophie im Rom des ersten Jahrhunderts 447-448. Herakleitos, Cornutus, das Buch $\pi$. xó $\mu \mu o v$ 448-451. Zweites Jahrhundert. Soziale Lage 45 1-454. Spielen von Althellas 454-459. Kultus. Feste 459-46r. Kultstätten 46I-465. Panathenäen 465-466. Verbindung priesterlicher Funktionen 466. Die eleusinischen Mysterien 467 bis 474. Späte Feste. Hadrian und Antinoos 474-476. Die fremden Götter. Astrologie. Philosophie 476-479. Apollonios von Tyana 479-482. Epiktet 482-485. Kaiser Marcus 485-487. Dion von Prusa 487-489. Maximus Tyrius 489. Plutarch 489 bis 497. Asklepios 497-498. Aristeides 498-500. Pausanias 50o bis 502. Lukian 502-504. Peregrinus Proteus und Alexandros von Abonuteichos 504-505. Die orphischen Hymnen 505-509. Der Zerfall des römischen Reiches. Diokletian s09-5 I I. Bruch mit dem Althellenischen $5 I_{1}-5 I_{3}$. Die letzten Sophisten $5 I_{3}$ bis 514 . Plotin $515-518$. Porphyrios $518-519$. Weitere beabsichtigte Darstellung 519-520. Cbristentum 520-\$23. Fragmente für den Scbluß 522-\{23. Aphorismen 522. Scblußpartie von "Neujabr 1900" $523-524$.

Beilagen.

1. Herakleides Pontikos $\pi \varepsilon \varrho i \tau \tilde{\omega} \nu$ غ̇ ${ }^{\circ} A \iota \delta o v$ 525.

2. Die Mysterien von Andania 528.

3. Klagen über den Verfall der Beredsamkeit 536 .

Nachträge so.

Register.

I. Namen und Sachen 544 .

II. Literatur und Stellen 589 .

III. Neuzeit 6rg. 
